\title{
Comparing and taming the reactivity of HWE and Wittig reagents with cyclic hemiacetals
}

\author{
Jokin Carrillo, Anna M. Costa ${ }^{*}$, Mireia Sidera, Jaume Vilarrasa ${ }^{*}$ \\ Departament de Química Orgànica, Facultat de Química, Universitat de Barcelona, Diagonal 647, 08028 Barcelona, Catalonia, Spain
}

\section{A R T I C L E IN F O}

\section{Article history:}

Received

Revised

Accepted ..........

Available online ......

\section{Keywords:}

Lactols

Wittig and HWE reactions

Oxa-Michael cyclisation

\begin{abstract}
A B S T R A C T
A practical solution to the formation of mixtures of $E / Z$ and open/cyclic isomers in the reaction of (2R,4S)-4-hydroxy-2-methylpentanal (as its hemiacetal, a lactol) with conjugated phosphoranes (stabilised Wittig reagents) and Horner-Wadsworth-Emmons reagents is disclosed. The HWE reaction has a strong bias to give oxolanes. On the other hand, stabilised Wittig reagents give unsaturated carboxyl derivatives of configuration $E$ (major) and oxolanes (minor); the latter can be avoided by addition of $\mathrm{CF}_{3} \mathrm{CH}_{2} \mathrm{OH}$ or using morpholine amide phosphorane.
\end{abstract}

(C) 2011 Elsevier Ltd. All rights reserved
In a total synthesis of amphidinolides $\mathrm{B} / \mathrm{D} / \mathrm{H} / \mathrm{G}$ under way (see the plans for B1 in Scheme 1$)^{1}$ we obtained erratic results in a Wittig-like double bond formation. Whereas we had no trouble in preparing fragment $\mathrm{C} 1-\mathrm{C} 6$ and a precursor of fragment C7-C13, fragment C20-C25 posed technical difficulties. We envisaged synthesising it from enantiopure 4-hydroxy-2-methylpentanal (1) via a double-bond formation (to obtain 2) followed by Sharpless asymmetric dihydroxylation. However, we knew ${ }^{2}$ that heating 1 , which exists in its cyclic hemiacetal forms (1'/1', 60:40), with the stabilised Wittig reagent $\mathrm{Ph}_{3} \mathrm{P}=\mathrm{CHCOOEt}$ would give the $(E)$-unsaturated ester impurified by $7 \%$ of its $Z$ isomer (which could not be

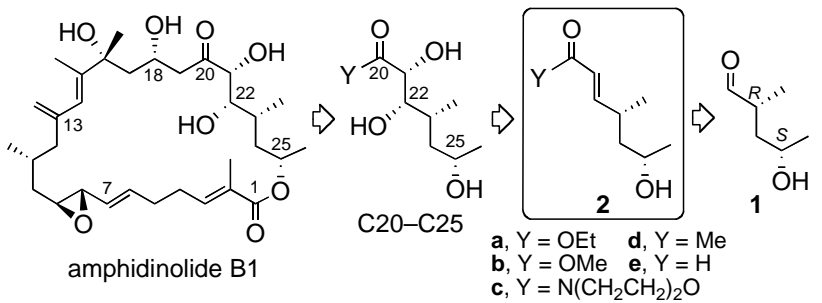

Scheme 1. Retrosynthesis of fragment C20-C25 of amphidinolide B1. separated by flash chromatography). ${ }^{2}$ We needed to avoid stereoisomeric mixtures, as we required stereopure $\mathrm{C} 20$ C25 fragments. We synthesised 1/1'/1', in four steps, in $50 \%$ overall yield, from O-protected (S)-2-hydroxypropanal $^{3}$ and treated the equilibrium mixture (Scheme 2) with $\mathrm{Ph}_{3} \mathrm{P}=\mathrm{CHCOOEt}$ in toluene at room temperature (rt) up to the consumption of the starting material. The crude product contained the desired compound, 2a (70\%), ca. $5 \%$ of its $Z$ isomer and $20 \%$ of a cyclic product (oxolane/oxolan 3a, impurified by 3a', ca. 2\%), arising from the addition in situ of the hydroxy group of $\mathbf{2 a}$ to the conjugated double bond. Moreover, heating 1'/1'’ with

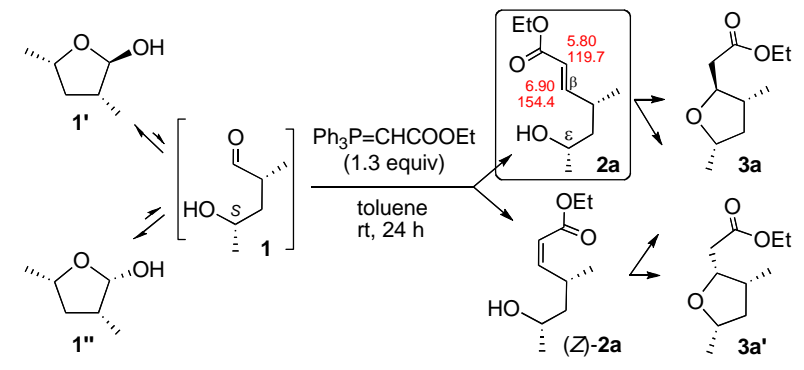

Scheme 2. Reaction of $\mathbf{1}$ with a standard stabilised phosphorane.

$\mathrm{Ph}_{3} \mathrm{P}=\mathrm{CHCOOEt}$ or with $\mathrm{Ph}_{3} \mathrm{P}=\mathrm{CHCOOMe}$ in toluene at $80{ }^{\circ} \mathrm{C}$ for a few hours gave $\mathbf{2 a}$ and $\mathbf{2} \mathbf{b}$, respectively, as the major products (ca. 60\%), but with percentages of cyclic

\footnotetext{
* Corresponding authors. Tel.: +34 93 4021258, fax: +34 933397878

E-mail addresses: amcosta@ub.edu,jvilarrasa@ub.edu
} 
products $\mathbf{3 a}$ and $\mathbf{3 b}$ around $30 \%$ (again, $\mathbf{3 a}$ and $\mathbf{3 b}$ contained minor amounts of 3a' and 3b', respectively).

Many similar ring openings of 5- and 6-membered lactols can be found in the literature. ${ }^{4}$ The base-catalysed, oxa-Michael cyclisation of the resulting $\varepsilon$-hydroxy and $\zeta$ hydroxy $\alpha, \beta$-unsaturated esters is a common procedure to prepare furan ${ }^{5}$ and pyran derivatives, respectively. Often the oxolane-containing moieties of other amphidinolides are constructed in such a way, ${ }^{5 b, f}$ but in our case we were not interested in the second step. We report how to avoid the "undesired cyclic by-products", in a case in which, possibly owing to the spatial relationship of the methyl groups, ${ }^{6}$ the $\varepsilon$-hydroxy unsatured substrates, $\mathbf{2 a}$ and $\mathbf{2 b}$, are quite prone to cyclisation.

First, we examined the reactions of 1'/1', with phosphonates (Table 1) with the expectation of shortening the reaction times, as the anions of HWE reagents are more basic $^{7}$ and nucleophilic than stabilised phosphoranes. As shown in Table 1, oxolanes $\mathbf{3}$ always predominated: ${ }^{8}$ oxolane $\mathbf{3 a}$ in entries $1-3$, under standard conditions; oxolane 3d from diethoxyphosphinylacetone (entry 4); even with a defect of base (entries 5-7). Quenching the reactions at shorter reaction times did not provide a solution, since the oxa-Michael or cyclisation step was more rapid than the phosphonate attack at the hidden $\mathrm{CHO}$ and the loss of $(\mathrm{EtO})_{2} \mathrm{P}(=\mathrm{O}) \mathrm{O}^{-}$(see Scheme 3 for a simplified explanation,

Table 1.

Screening of the reactivity of $\mathbf{1}$ with HWE reagents. ${ }^{a}$

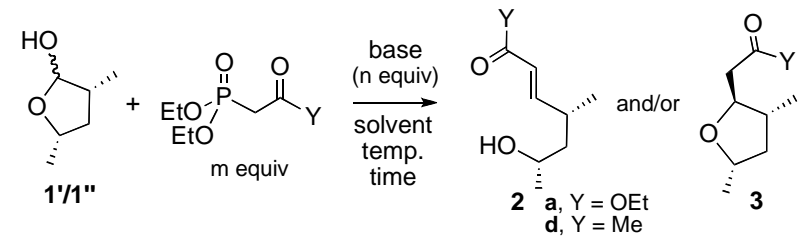

\begin{tabular}{|c|c|c|c|c|c|c|c|c|c|}
\hline Entry & Y & $\mathrm{m}$ & Base & $\mathrm{n}$ & Solv. & $\begin{array}{c}\text { Temp. } \\
\left({ }^{\circ} \mathrm{C}\right)\end{array}$ & $\begin{array}{c}\text { Time } \\
(\mathrm{h})\end{array}$ & $\begin{array}{l}\text { Conv. } \\
(\%)\end{array}$ & $\begin{array}{l}2 / 3 \\
\text { Ratio }^{\mathrm{b}}\end{array}$ \\
\hline 1 & OEt & 1.3 & DBL & 1.1 & tolu & 80 & 16 & 100 & $0: 100$ \\
\hline 2 & OEt & 1.3 & & & $1 \mathrm{H}$ & 65 & 1 & 100 & :10 \\
\hline 3 & OEt & 1.2 & $\mathrm{DBU}^{\mathrm{c}}$ & 1.1 & $\mathrm{CH}_{3} \mathrm{CN}$ & $\mathrm{rt}$ & 16 & 100 & $0: 100$ \\
\hline 4 & $\mathrm{Me}$ & 1.2 & $\mathrm{DBU}^{\mathrm{c}}$ & 1.0 & $\mathrm{CH}_{3} \mathrm{CN}$ & $\mathrm{rt}$ & 16 & 95 & $0: 100$ \\
\hline 5 & OEt & 1.0 & $\mathrm{DBU}^{\mathrm{c}}$ & 0.8 & $\mathrm{CH}_{3} \mathrm{CN}$ & $\mathrm{rt}$ & 16 & 68 & 10:90 \\
\hline 6 & OEt & 1.2 & $\mathrm{Cs}_{2} \mathrm{CO}_{3}{ }^{\mathrm{d}}$ & 0.9 & ${ }^{\mathrm{i}} \mathrm{PrOH}$ & $\mathrm{rt}$ & 16 & 100 & $0: 100$ \\
\hline 7 & OEt & 1.2 & KHMDS $^{\mathrm{e}}$ & 1.1 & THF & $-78 / \mathrm{rt}^{\mathrm{e}}$ & 1 & 77 & $20: 80$ \\
\hline
\end{tabular}

a From $0.5-0.8 \mathrm{mmol}$ of $\mathbf{1} / 1$ '” in $5 \mathrm{~mL}$ of solvent $(0.10-0.16 \mathrm{M})$.

${ }^{\mathrm{b}}$ As determined by $400-\mathrm{MHz}{ }^{1} \mathrm{H}$ NMR. Ratios 0:100 and 100:0 mean that the minor compound was not detected $(\leq 1 \%)$.

c With $\mathrm{LiCl}$ as an additive, as it is common practice, see Ref. 9 .

${ }^{d} \mathrm{Cs}_{2} \mathrm{CO}_{3}$ in isopropanol is useful in many HWE reactions, see Ref. 10 . We also attempted reactions with $\mathrm{Cs}_{2} \mathrm{CO}_{3}(90 \mathrm{~mol} \%)$ in $\mathrm{CF}_{3} \mathrm{CH}_{2} \mathrm{OH}$ and in toluene, but no attack took then place at $\mathrm{rt}$, whereas 3 was formed too quickly on heating. Magnesium salts (prepared from the phosphonate and $\mathrm{RMgX}$ ) did not work either.

${ }^{\mathrm{e}}$ Plus 18 -crown-6, see Ref. 9. After $1 \mathrm{~h}$ at $-78{ }^{\circ} \mathrm{C}$, the reaction was allowed to warm up to $\mathrm{rt}$ (as there was no reaction below rt), and stirring was maintained for one further hour.

according to the accepted mechanism of HWE reactions, ${ }^{9}$ where :B may be the phosphonate anion itself). A very low temperature was contra-indicated, as the percentage of the reactive form (1) in the equilibrium is minute, so the first step - the attack of the anion of the phosphonate - did not progress. If the medium was not basic, the oxy-phosphonate adduct would not eliminate $(\mathrm{EtO}){ }_{2} \mathrm{P}(=\mathrm{O}) \mathrm{O}^{-}$. In other words, a basic medium is crucial for the initial steps but it also catalyses the unwanted final oxa-Michael reaction. Thus, we were unable to control the HWE reaction of 1'/1', i.e., to tame the strong tendency of $\mathbf{2}$ to cyclise to $\mathbf{3}$ under the conditions required for a successful HWE reaction. ${ }^{11}$

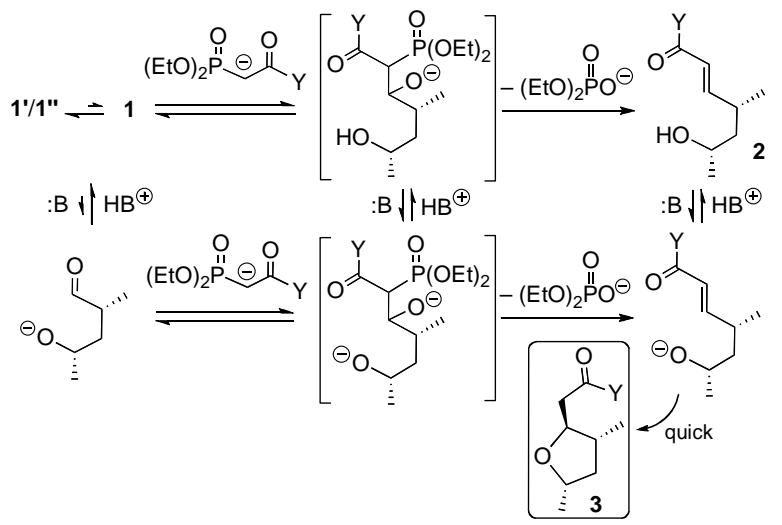

Scheme 3. HWE reaction of 1/1'/1'”

The morpholine amide derivative of the phosphonate, (EtO) $)_{2} \mathrm{POCH}_{2} \mathrm{CON}\left(\mathrm{CH}_{2} \mathrm{CH}_{2}\right) \mathrm{O},{ }^{12}$ i.e. with $\mathrm{Y}=$ morpholin4-yl in Table 1 and Scheme 3, was also examined, without success. In polar and basic media (as in entry 3 of Table 1) oxolane 3c predominated. With $\mathrm{Ba}(\mathrm{OH})_{2}$ in moist THF, the attack of that phosphonate did not occur even on heating. With DBU in less polar media, such as toluene, there was no attack at rt, whereas on heating the cyclisation to oxolane 3c again turned out to be more rapid than the previous steps.

In sharp contrast, this is not the case for simple lactol 4', the internal hemiacetal of 4-hydroxybutanal (4), ${ }^{13}$ for which both the open and cyclic forms are clearly observed by NMR. We re-examined its reaction with the standard HWE reagent and $\mathrm{DBU}$ in $\mathrm{CH}_{3} \mathrm{CN}$ (Scheme 4). Only the open unsaturated ester (5a) ${ }^{14}$ was obtained (under conditions in which 2a completely or largely cyclised to 3a). The corresponding morpholine amide (5c) was obtained similarly, in excellent yield.

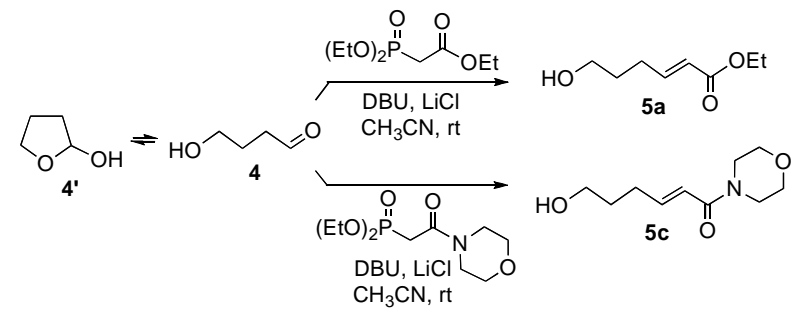

Scheme 4. HWE reactions of 4. 
In view of the disappointing results with 1'/1', and HWE reagents, we returned to the stabilised Wittig $(\mathrm{sW})$ reagents. At least, in our preliminary experiments the oxolanes had been the minor compounds. Assuming that the "premature" or unwanted cyclisation of $\mathbf{2 a}$ is catalysed by any base present, even the excess of a very moderate base like phosphorane $\mathrm{Ph}_{3} \mathrm{P}=\mathrm{CH}-\mathrm{COOEt}$ should be avoided. We changed the reagent ratio, adding dropwise 0.9 equiv of phosphorane to $\mathbf{1} / \mathbf{1}$ ', in toluene at $80^{\circ} \mathrm{C}$. Only (E)-2a was formed, but it had to be separated from the remaining starting material.

Bearing in mind that $\mathbf{1} / \mathbf{1}$ '” is more expensive than the phosphorane, we developed a better "trick". We used 1.3 equiv of phosphorane $\mathrm{Ph}_{3} \mathrm{P}=\mathrm{CHCOOEt}$ but added 2,2,2trifluoroethanol $\left(\mathrm{CF}_{3} \mathrm{CH}_{2} \mathrm{OH}, \mathrm{pK}=12.2 \text { in water }\right)^{15}$ to the reaction mixture. In practice, $200 \mathrm{~mol} \%$ was enough. The moderate acidity of the hydroxy group of trifluoroethanol disturbed or blocked the base-catalysed conjugate addition of the $\varepsilon$-hydroxy group of 2a. The desired (E)-2a was obtained quantitatively, within $48 \mathrm{~h}$ at rt, in a pure condition (Scheme 5, top).

We also prepared the morpholine amide-containing phosphorane $\mathrm{Ph}_{3} \mathrm{P}=\mathrm{CHCON}\left(\mathrm{CH}_{2} \mathrm{CH}_{2}\right)_{2} \mathrm{O}$, a known compound, ${ }^{16}$ but, to our knowledge, never used in synthesis. By contrast, the corresponding Weinreb amide is commercially available and has been utilised in over 50 papers (SciFinder search). ${ }^{17}$ By heating this morpholinecontaining phosphorane and 1'/1', without any precautions and without any additive, the desired 2c was obtained quantitatively (Scheme 5 , bottom). ${ }^{18}$ We attributed the lack of oxolane formation to the poorer EW character of the amide group with regard to an ester group. In fact, in an independent experiment, a mixture of 2a and 2c was treated in an NMR tube, in $\mathrm{CDCl}_{3}$, with DBU at rt; unsaturated ester 2a fully cyclised in 2-3 days, whereas unsaturated amide $2 \mathrm{c}$ remained unaltered (however, the cyclisation of 2c to $3 \mathbf{c}$ took place in the more polar solvent $\mathrm{CH}_{3} \mathrm{CN}$ by addition of $\mathrm{NaH}$ ).

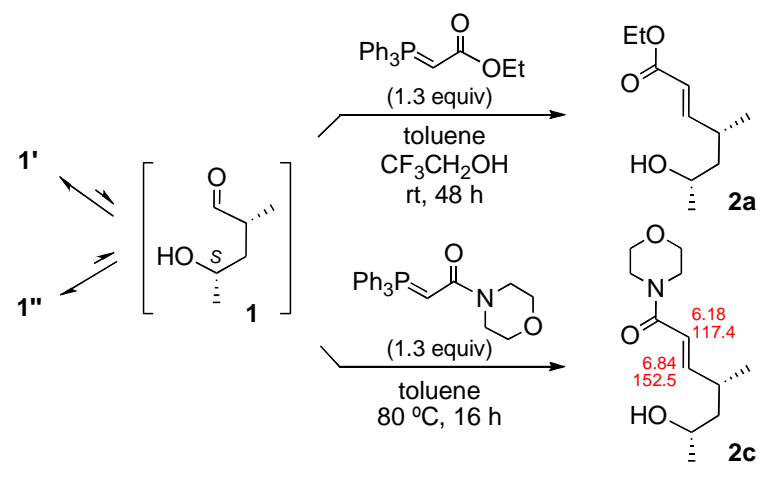

Scheme 5. Reactions of $\mathbf{1}$ with phosphoranes.

Since morpholine amides are cheap alternatives to Weinreb amides for the conversion of carboxy derivatives into ketones (with $\mathrm{RLi}$ or $\mathrm{RMgX}$ ) or aldehydes (with DIBALH), ${ }^{19}$ the access to $\mathbf{2 d}$ and $2 \mathbf{e}$ of Scheme 1 was guaranteed.
These two synthetic tricks can be instrumental in lactols that are very stable and may give rise to $\varepsilon$ - or $\zeta$ hydroxy $\alpha, \beta$-unsaturated esters in which the respective formation of 5- or 6-membered rings is very favoured. ${ }^{20}$

In summary, lactol $1 \% / 1$ ' is a model of very stable cyclic hemiacetalic forms of hydroxy-aldehydes. Their derivatives, with $\mathrm{CH}=\mathrm{CH}-\mathrm{EWG}$ instead of $\mathrm{CH}=\mathrm{O}$, show a similar strong tendency to form stable oxolanes (THF derivatives as very major products). If these are required, as happens in many cases, even in the total synthesis of several oxolane-containing amphidinolides other than those we are dealing with, this is an advantage. In fact, the HWE reactions, without base other than the phosphonate anion, are spontaneously followed by an oxa-Michael cyclisation (which cannot be tamed). In the light of Table 1 , the title of this paper could have been "one-pot conditions for obtaining oxolanes of type $\mathbf{3}$ from lactols in excellent yieds (impurified only by small amounts of 3')". However, our goal was not $\mathbf{3}$ but 2.

When $\varepsilon$-hydroxy $\alpha, \beta$-unsaturated carboxyl derivatives (open compounds 2) are desired, we have disclosed two useful tricks to tame the weaker tendency of sW reagents to give rise to oxolanes as by-products: (i) to carry them in the presence of $\mathrm{CF}_{3} \mathrm{CH}_{2} \mathrm{OH}$ or (ii) to use the morpholine amide of the phosphonium ylide.

\section{Acknowledgments}

This study was started with funds from grant CTQ2006-15393 (Spanish Government, Madrid) and continued with grant CTQ2009-13590 and with a gift of the AGAUR (2009SGR-825, GRC Stereoselective Synthesis of Antitumour and Antiviral Agents). M.S. deeply thanks the AGAUR, Generalitat de Catalunya, Barcelona, for a doctorate studentship (2007-2010). J.C. has had a CTQ2009-linked studentship since mid-2010. Thanks are due to Prof. M. F. Semmelhack (Princeton University) for exchange of NMR information (Ref. 8a).

\section{Supplementary data}

Supplementary data (copies of ${ }^{1} \mathrm{H}$ and ${ }^{13} \mathrm{C}$ NMR spectra, ${ }^{1} \mathrm{H}$ NMR spectra of the reaction of $2 \mathbf{a}$ and $2 \mathrm{c}$ with DBU) associated with this article can be found, in the online version, at doi:

\section{References and notes}

1. For total syntheses already published, see: (a) Fürstner, A.; Bouchez, L. C.; Funel, J.-A.; Liepins, V.; Poree, F.-H.; Gilmour, R.; Beaufils, F.; Laurich, D.; Tamiya, M. Angew. Chem., Int. Ed. 2007, 46, 9265-9270; (b) Lu, L.; Zhang, W.; Carter, R. G. J. Am. Chem. Soc. 2008, 130, 7253-7255; (c) Fürstner, A.; Bouchez, L. C.; Morency, L.; Funel, J.-A.; Liepins, V.; Poree, F.-H.; Gilmour, R.; Laurich, D.; Beaufils, F.; Tamiya, M. Chem. Eur. J. 2009, 15, 3983-4010.

2 Barrett, A. G. M.; Carr, R. A. E.; Attwood, S. V.; Richardson, G.; Walshe, N. D. A. J. Org. Chem. 1986, 51, 4840-4856. 
3. By means of a Still-Gennari reaction from (2S)-2-(tetrahydropyran-2-yloxy)propanal, with ethyl 2-[bis(2,2,2-trifluoroethoxy)phosphinyl]propanoate prepared according to: (a) Patois, C.; Savignac, P. Synth. Commun. 1991, 21, 2391-2396. After removal of the THP group and formation of the lactone in acidic media, the stereoselective hydrogenation was achieved with $\mathrm{Rh} / \mathrm{Al}_{2} \mathrm{O}_{3}$ in agreement with: (b) Kang, S.-K.; Lee, D.-H. Synlett. 1991, 175-176. Reduction with DIBALH in THF at $-78{ }^{\circ} \mathrm{C}$ afforded the lactol (1'/1') in good yield.

4. For representative examples, see: (a) Shi, L.; Lei, X.; Zhang, J.; Lin, G. Helv. Chim. Acta 2010, 93, 555-564; (b) Reynolds, N. T.; Rovis, T. Tetrahedron 2005, 61, 6368-6378; (c) Maier, C. A.; Wünsch, B. J. Med. Chem. 2002, 45, 4923-4930; (d) Haselgrove, T. D.; Jevric, M.; Taylor, D. K.; Tiekink, E. R. T. Tetrahedron 1999, 55, 14739-14762.

5. For a classical review, see: (a) Little, R. D.; Masjedizadeh, M. R.; Wallquist, O.; McLoughlin, J. I. Org. React. 1995, 47, 315-552; for very recent examples, see: (b) Paudyal, M. P.; Rath, N. P.; Spilling, C. D. Org Lett. 2010, 12, 2954-2957; (c) Fuwa, H.; Yamaguchi, H.; Sasaki, M. Org Lett. 2010, 12, 1848-1851; (d) Rao, G. S.; Sudhakar, N.; Rao, B. W.; Basha, S. J. Tetrahedron: Asymmetry 2010, 21, 1963-1970; (e) Enders, D.; Wang, C.; Greb, A. Adv. Synth. Catal. 2010, 352, 987-992; (f) Armstrong, A.; Pyrkotis, C. Tetrahedron Lett. 2009, 50, 3325-3328; (g) Ghosh, A. K.; Shurrush, K.; Kulkarni, S. J. Org. Chem. 2009, 74, 4508-4518; (h) Jenkinson, S. F.; Booth, K. V.; Estévez-Reino, A. M.; Horne, G.; Estévez, R. J.; Fleet, G. W. J. Tetrahedron: Asymmetry 2009, 20, 2357-2367.

6. Review on conformational preferences of acyclic compounds: (a) Hoffmann, R. W. Angew. Chem. Int. Ed. 2000, 39, 2054 2070; for the easier cyclisation of a syn-1,3-dimethyl hydroxycarboxyl derivative, see: (b) Mas, G.; Gonzàlez, L.; Vilarrasa, J. Tetrahedron Lett. 2003, 44, 8805-8809.

7. The basicity of $\mathrm{Ph}_{3} \mathrm{P}=\mathrm{CHCOOEt}$ is weak, since its conjugate acid is relatively strong $\left(\mathrm{p} K_{\mathrm{a}} 8.5\right.$ in DMSO, several units lower in water). In sharp contrast, the methylene protons of $(\mathrm{EtO})_{2} \mathrm{POCH}_{2} \mathrm{COOEt}$ have an estimated $\mathrm{p} K_{\mathrm{a}}$ value in DMSO of 18.6. It means that the basicity of the HWE reagent (the anion) is ca. 10 units stronger than that of the sW reagent. See: (a) Qi, C.; Du, Y.; Lu, Y.; Sun, X., Zhang, X.-M. J. Org. Chem. 2009, 74, 8078-8085; (b) Zhang, X.-M.; Bordwell, F. G. J. Am. Chem. Soc. 1994, 116, 968-972; also see: (c) http://www.chem.wisc.edu/areas/reich/pkatable/kaphos.gif.

8. One oxolane stereoisomer was formed mainly in each case, as depicted in Table 1, with the side chain at $\mathrm{C} 2$ and $\mathrm{Me}$ at $\mathrm{C} 3$ in trans. Ratios 3a/3a' and 3d/3d' were between 90:10 and 95:5. The relative configuration of $3 \mathbf{a}$ was assigned by NOESY experiments and by comparison with available NMR data of very similar structures: (a) Semmelhack, M. F.; Zhang, N. J. Org. Chem. 1989, 54, 4483-4485. (b) Homma, K.; Takenoshita, H.; Mukaiyama, T. Bull. Chem. Soc. Jpn. 1990, 63, 1898-1915.

9 (a) For a classical review, see: Maryanoff, B. E.; Reitz, A. B. Chem. Rev. 1989, 89, 863-927; for the relative nucleophilicities of P-stabilised carbanions, see: (b) Appel, R.; Loos, R.; Mayr, H. J. Am. Chem. Soc. 2009, 131, 704-714; also see the following papers and references therein: (c) Blasdel, L. K.; Myers, A. G. Org. Lett. 2005, 7, 4281-4283 (use of fluorinated alkoxides); (d) Bonini, C.; Chiummiento, L.; De Bonnis, M.; Funicello, M.; Lupattelli, P. Tetrahedron Lett. 2004, 45, 2797-2799; (e) Motoyoshiya, J.; Kusaura, T.; Kokin, K.; Yokoya, S.; Takaguchi, Y.; Narita, S.; Aoyama, H. Tetrahedron 2001, 57, 1715-1721.

10. (a) Uenishi, J.; Iwamoto, T.; Tanaka, J. Org. Lett. 2009, 11, 32623265; (b) Roy, S.; Spilling, C. D. Org. Lett. 2010, 12, 5326-5329.

11. An alternative approach may be suggested, based on a suitable opening of lactol 1'/1', followed by the protection of the hydroxy group and a standard HWE reaction with the $\mathrm{CHO}$ group once deprotected, but it meant additional synthetic steps. The direct protection of the hydroxy group is sometimes appropriate for lactols not substituted at $\mathrm{C} 5$, the open form of which is a more reactive primary alcohol (in general, when the $\mathrm{OH}$ group of the open form is less congested than the $\mathrm{OH}$ group of the lactol): (a) Yau, E. K.; Coward, J. K. J. Org. Chem. 1990, 55, 3147-3158; (b) Sibley, R.; Hatoum-Mokdad, H.; Schoenleber, R.; Musza, L.; Stirtan, W.; Marrero, D.; Carley, W.; Xiao, H.; Dumas, J. Bioorg. Med. Chem. Lett. 2003, 13, 1919-1922; (c) Paintner, F. F.; Bauschke, G.; Polborn, K. Tetrahedron Lett. 2003, 44, 25492552; (d) Kim, W. H.; Park, A.-Y.; Kang, J.-A.; Kim, J.; Kim, J.A.; Lee, H.-R.; Chun, P.; Choi, J.; Lee, C.-K.; Jeong, L. S.; Moon, H. R. Tetrahedron 2010, 66, 1706-1715; (e) Graham, T. J. A.; Gray, E. E.; Burgess, J. M.; Goess, B. C. J. Org. Chem. 2010, 75, 226-228. However, in the case of 1'/1', different attempts (with LiHMDS in THF at $-78{ }^{\circ} \mathrm{C}$ followed after equilibration by addition of TBSCl and warming up to rt, with LiHMDS and $\mathrm{TBSCl}$ by direct mixing in THF at $\mathrm{rt}$, with KHMDS at $-78^{\circ} \mathrm{C}$ and heating later at $60^{\circ} \mathrm{C}$ with TBDPSCl) led to the TBS- or TBDPS-protected cyclic form (lactol) as the major product.

12. Preparation: Grzyb, J. A.; Shen, M.; Yoshina-Ishii, C.; Chi, W.; Brown, R. S.; Batey, R. A. Tetrahedron Lett. 2005, 61, 71537175.

13. (a) Stephens, B. E.; Liu, F. J. Org. Chem. 2009, 74, 254-263; for illustrative lactol openings of simple C4-substituted derivatives, see: (b) Roush, W. R.; Gillis, H. R.; Ko, A. I. J. Am. Chem. Soc. 1982, 104, 2269-2283; (c) Nagasawa, K.; Hori, N.; Koshino, H.; Nakata, T. Heterocycles 1999, 50, 919-928; (d) Sinha, S. C.; Sinha, S. C.; Keinan, E. J. Org. Chem. 1999, 64, 7067-7073; (e) Hoye, T. R.; Eklov, B. M.; Jeon, J.; Khoroosi, M. Org. Lett. 2006, 8, 3383-3386.

14. We had to add $\mathrm{NaH}$ to the resulting solution of $\mathbf{5 a}$ to cause its cyclisation to $\mathbf{6 a}$, which took then place in $3 \mathrm{~h}$.

15. The $\mathrm{p} K_{\mathrm{a}}$ value of $\mathrm{CF}_{3} \mathrm{CH}_{2} \mathrm{OH}$ in DMSO is 23.5 , according to Ref. $7 \mathrm{~b}$; that of $\mathrm{EtOH}$ is 29.8 . For the use of $\mathrm{CF}_{3} \mathrm{CH}_{2} \mathrm{OH}$ as a protic co-solvent in another context, see: Arjona, O.; Medel, R.; Rojas, J.; Costa, A. M.; Vilarrasa, J. Tetrahedron Lett. 2003, 44, 63696373.

16. Chopard, P. A. J. Org. Chem. 1966, 31, 107-111.

17. We have been unable to find examples of opening of 5membered lactols with such a phosphorane, but there is one from a 6-membered lactol: Nakamura, S.; Inagaki, J.; Sugimoto, T.; Ura, Y.; Hashimoto, S. Tetrahedron 2002, 58, 10375-10386.

18. Besides, the $E$ selectivity is higher. The trend of the Weinreb amides of sW, HWE and Ando reagents to afford higher selectivities than the corresponding $E$ or $Z$ esters is known: Ando, K.; Nagaya, S.; Tarumi, Y. Tetrahedron Lett. 2009, 50, 5689-5691, and ref. 10 cited therein; morpholine amides of Ando reagents also give higher $Z / E$ ratios.

19. (a) Martín, R.; Romea, P.; Tey, C.; Urpí, F.; Vilarrasa, J. Synlett 1997, 1414-1416; (b) Kurosu, M.; Kishi, Y. Tetrahedron Lett. 1998, 39, 4793-4796; (c) Olivella, A.; Rodríguez-Escrich, C.; Urpí, F.; Vilarrasa, J. J. Org. Chem. 2008, 73, 1578-1581, and references therein.

20. Other possible routes cannot be recommended. For example, simple aldehydes react with ethyl 4,4,4-trifluoro-2-oxobutyrate $\left(\mathrm{CF}_{3} \mathrm{COCH}_{2} \mathrm{COOEt}\right)$ and piperidine to give $(E)-\alpha, \beta$-unsaturated esters, with elimination of the $\mathrm{CF}_{3} \mathrm{CO}$ group. See: Raju, B. C.; Suman, P. Chem. Eur. J. 2010, 16, 11840-1842. We confirmed that this reaction did work with PhCHO. However, 1'/1" did not, even from the $\mathrm{CF}_{3} \mathrm{COCH}_{2} \mathrm{COOEt}$ anion (with $\mathrm{NaH}$ ) and $\mathbf{1} / \mathbf{1}$ '” in refluxing $\mathrm{CH}_{3} \mathrm{CN}$, likely owing to the very low concentration of the reactive, open form (1). 


\section{Graphical abstract}

Comparing and taming the reactivity of HWE and Wittig reagents with cyclic hemiacetals

Jokin Carrillo, Anna M. Costa*, Mireia Sidera, Jaume Vilarrasa*
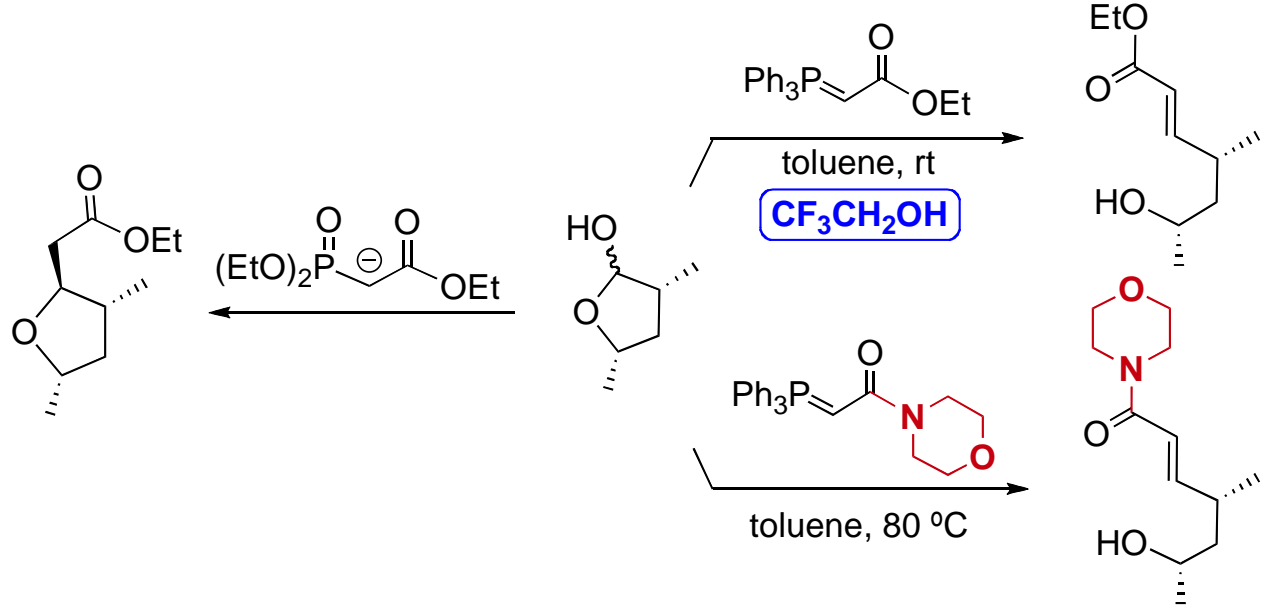